\title{
PERENCANAAN TEBAL PERKERASAN JALAN DAN RAB JALAN RAYA GLENMORE KABUPATEN BANYUWANGI \\ ( Perbandingan Metode Bina Marga tahun 1987 dan 2013 )
}

\author{
Ahmad Basit Bustomi ${ }^{1}$, Irawati ${ }^{2}$, Taufan Abadi ${ }^{3}$ \\ Program Studi Teknik Sipil Fakultas Teknik Universitas Muhammadiyah Jember ${ }^{1}$ \\ JL. Karimata 49 Jember Telp: (0331) 332240 Fax: (0331) 337957 \\ Email: Tomi.fixie@gmailcom \\ Program Studi Teknik Sipil Fakultas Teknik Universitas Muhammadiyah Jember ${ }^{2}$ \\ JL. Karimata 49 Jember Telp: (0331) 332240 Fax: (0331) 337957 \\ Program Studi Teknik Sipil Fakultas Teknik Universitas Muhammadiyah Jember ${ }^{3}$ \\ JL. Karimata 49 Jember Telp: (0331) 332240 Fax: (0331) 337957
}

\begin{abstract}
ABSTRAK
Glenmore Highway, Banyuwangi Regency is a highway that borders the Kalibaru Highway and the Genteng Highway Banyuwangi Regency. As is known, the Glenmore highway of Banyuwangi regency is an eastern crossroad of various destinations. For example, heavy vehicles (transportation) from Java to the island of Bali or vice versa which will pass the Glenmore highway of Banyuwangi district, especially on KM 250 - this KM.252. Heavy vehicles that pass the Glenmore highway in Banyuwangi district have different destinations. Heavy vehicles that pass the Glenmore highway in Banyuwangi district have different destinations. For example trailer trucks or semi-trailers transporting commodity goods or other goods. The location of this research is a strategic location that is close to or leads to distributor warehouses located in Glenmore, Banyuwangi Regency. With these conditions, it is necessary to evaluate the thickness of the pavement on the road. With the evaluation of the pavement thickness calculation and the calculation of the budget plan, it will later provide a new alternative or contribute technical thinking in determining the thickness of the pavement layer and its the calculation of the budget plan.
\end{abstract}

Keywords: Planning, pavement layer, Calculation of Budget Plan, Banyuwangi

\section{PENDAHULUAN}

\section{Latar Belakang}

Prasarana berupa jalan raya merupakan akses darat yang harus diperhatikan fisiknya. Pembangunan dan peningkatan prasarana transportasi darat (jalan) dapat menunjang kelancaran dan pemerataan pembangunan di daerah maupun Nasional. Pada .jalan raya Glenmore kabupaten Banyuwangi ini merupakan jalan raya yang berbatasan dengan jalan raya Kalibaru dan Jalan raya Genteng Kabupaten Banyuwangi. Lokasi penelitian ini merupakan lokasi strategis yang berdekatan atau mengarah gudang-gudang distributor yang berada di jalanraya Glenmore kabupaten Banyuwangi. Bus-bus dengan tujuan pariwisata ke pulau Bali dan angkutan penumpang atau dengan tujuan antar kabupaten, Dengan evaluasi perhitungan tebal perkerasan dan perhitungan rencana anggaran biaya (RAB), nantinya akan memberi alternative baru atau sumbangsih pemikiran secara teknis dalam menetukan tebal lapisan perkerasan jalan dan RAB.

\section{Rumusan Masalah}

Pada perumusan masalah dalam penelitian dan pembahasan Tugas akhir ini, adalah :

1. Bagaimana kinerja jalan raya Glenmore kabupaten Banyuwangi pada KM.250-KM.252 saat ini?

2. Bagaimana kondisi perkerasan jalan raya Glenmore Kabupaten Banyuwangi pada KM.250 - KM.252 saat ini?

3. Bagaimana menentu kan tebal pekerasan dengan metode Bina Marga 1987 dan 2013 dengan Usia Rencana 20 tahun kedepan?

4. Bagaimana hasil dari perbandingan dari hasil perhitungan metode Bina Marga1987 dan 2013? 
5. Bagaimana perbandingan Rencana Anggaran Biaya (RAB).

\section{Tujuan Penelitian}

Menganalisa kinerja jalan pada jalan raya Glenmore Kabupaten Banyuwangi pada KM.250 - KM.252.

1 Menganalisa kondisi eksiting struktur perkerasan jalan raya Glenmore Kabupaten Banyuwangi pada KM.250 KM.252 saat ini?

2 Menganalisa perencanaan tebal perkerasan dengan perbandingan metode Bina Marga 1987 dan 2013 dengan Usia Rencana 20 tahun.

3 Menganalisa hasil perbandingan dengan metode Bina Marga 1987 dan 2013.

4 Merencanakan dan membandingkan anggaran biaya (RAB) dari hasil perhitungan metode Bina Marga 1987 dan 2013.

\section{TINJAUAN PUSTAKA}

Definisi dari Kapasitas jalan sebagai arus maksimum melalui suatu titik di jalan yang dapat dipertahankan per satuan jamnya pada kondisi tertentu. Untuk jalan dua-lajur duaarah, kapasitas ditentukan untuk arus dua arah ( kombinasi dua arah), tetapi untuk jalan dengan banyak lajur, arus dipisahkan per arah dan kapasitas ditentukan per lajur (MKJI, 1997).

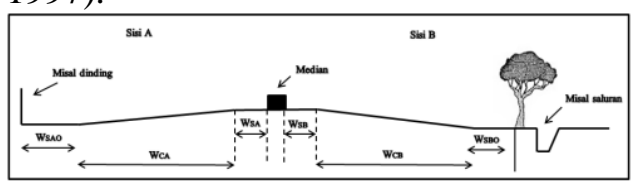

Gambar 1a. Pemisahan Lajur Jalan

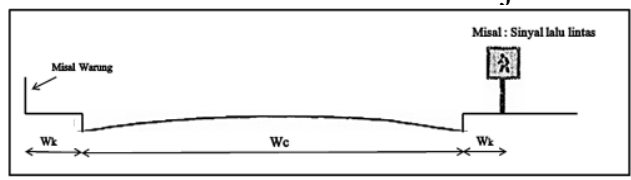

Gambar 1b. Pemisahan Lajur Jalan

Keterangan :

$\begin{array}{ll}\mathrm{W}_{\mathrm{CA}}, \mathrm{W}_{\mathrm{CB}} & : \text { Lebar jalur lalu lintas } \\ \mathrm{W}_{\mathrm{SAT}} & : \text { Lebar bahu dalam sisi A } \\ \mathrm{W}_{\mathrm{SAO}} & \text { : Lebar bahu luar sisi A } \\ \mathrm{W}_{\mathrm{C}} & \text { : Lebar jalur } \\ \mathrm{W}_{\mathrm{K}} & \text { : jarak dari kereb ke } \\ & \text { penghalang. }\end{array}$

Untuk nilai kapasitas telah diamati melalui pengumpulan data lapangan selama memungkinkan.Karena lokasi yang mempunyai arus mendekati kapasitas segmen jalan sedikit dan sebagaimana terlihat dari kapasitas simpang sepanjang jalan raya,
Kapasitas jalan luar kota di Indonesia dapat dihitung menggunakan persamaan MKJI (1997:18):

$\mathbf{C}=\mathbf{C}_{\mathbf{o}} \times \mathrm{FC}_{\mathrm{w}} \times \mathrm{FC}_{\mathrm{SF}} \times \mathrm{FC}_{\mathrm{C}}$

Sedangkan perhitungan derajat kejenuhannya dapat dihitung dengan rumus :

$$
\begin{aligned}
& \mathrm{DS}=\mathrm{Q} / \mathrm{C} \\
& \mathrm{C}=\mathrm{C}_{\mathrm{o}} \times \mathrm{FC}_{\mathrm{w}} \times \mathrm{FC}_{\mathrm{SF}} \times \mathrm{FC}_{\mathrm{CS}}
\end{aligned}
$$

Dimana :

$$
\begin{array}{ll}
\mathrm{C} & =\text { Kapasitas } \\
\mathrm{Co} & =\text { Kapasitas dasar } \\
\mathrm{FC}_{\mathrm{W}} & =\text { Faktor koreksi lebar masuk } \\
\mathrm{FC}_{\mathrm{SP}} & =\text { Faktor penyesuaian kapasitas }
\end{array}
$$

untuk pemisah arah

$\mathrm{FC}_{\mathrm{SF}}=$ Faktor penyesuaian kapasitas untuk hambatan samping dan bahu jalan atau kereb

$\mathrm{FC}_{\mathrm{C}}=$ Faktor penyesuaian kapasitas untuk ukuran kota (jumlah penduduk)

Sedangkan perhitungan derajat kejenuhannya dapat dihitung dengan rumus:

$$
\begin{aligned}
& \mathbf{D S}=\mathbf{Q} / \mathbf{C} \ldots \ldots \ldots \ldots \ldots \ldots \ldots \ldots(3) \\
& \text { Dimana : } \\
& \text { C : Kapasitas } \\
& \text { DS : Derajat Kejenuhan } \\
& \text { Q : Volume Kendaraan. }
\end{aligned}
$$

\section{Pengamatan Volume Kedaraan di Jalan}

Pada pengamatan LHR dilakukan dengan pengamatan langsung (primer) atau data didapat dari kantot/Dinas (Sekunder). Pada Satuan Mobil Penumpang (Smp) terdapat

\begin{tabular}{|c|c|c|c|c|}
\hline \multirow[t]{2}{*}{ No } & \multirow{2}{*}{$\begin{array}{c}\text { Jenis } \\
\text { Kendaraa } \\
\mathbf{n}\end{array}$} & \multirow{2}{*}{$\begin{array}{c}\text { Kel } \\
\text { as }\end{array}$} & \multicolumn{2}{|c|}{ SMP/Emp } \\
\hline & & & $\begin{array}{l}\text { Ru } \\
\text { as }\end{array}$ & $\begin{array}{c}\text { Simpa } \\
\text { ng }\end{array}$ \\
\hline 1 & $\begin{array}{l}\text { Sedan/jee } \\
\text { p, } \\
\text { oplet,micr } \\
\text { obus, pick } \\
\text { up }\end{array}$ & LV & $\begin{array}{c}1,0 \\
0\end{array}$ & 1,00 \\
\hline 2 & Bus & HV & 1,2 & 1,30 \\
\hline
\end{tabular}
adanya koefisien atau Ekivalen mobil penumpang (Emp) pada kendaraan bermotor maupun tak bermotor. Untuk besarnya koefisien pada masing-masing kendaraan bermotor atau tidak bermotor mempunyai nilai berbeda. Adapun besarnya koefisien pada kendaraan, sebagai berikut :

Tabel 1. Faktor Koreksi Kapasitas Akibat Ukuran Kota (FCcs) 


\begin{tabular}{|c|c|c|c|c|}
\hline & $\begin{array}{l}\text { Standar, } \\
\text { truk } \\
\text { sedang, } \\
\text { truk berat }\end{array}$ & & 0 & \\
\hline 3 & $\begin{array}{l}\text { Sepeda } \\
\text { motor }\end{array}$ & $\mathrm{MC}$ & $\begin{array}{c}0,2 \\
5\end{array}$ & 0,40 \\
\hline 4 & $\begin{array}{l}\text { Becak, } \\
\text { sepeda, } \\
\text { andong, } \\
\text { dll }\end{array}$ & UM & $\begin{array}{c}0,8 \\
0\end{array}$ & 1,00 \\
\hline
\end{tabular}

Sumber : MKJI, 1997.

Keterangan :

LV : Light vehicle (kendaraan kecil)

HV : High vehicle (kendaraan besar)

MC : Motor cycle (sepeda motor)

UM : Unmotorized vehicle (kendaraan tak bermotor).

\section{Peramalan Volume Lalu Lintas}

Untuk menganalisa kinerja jalan pada masa yang akan datang, maka diambil beberapa variabel yang mempengaruhi volume lalu lintas, antara lain : PDRB (Pendapatan Domestik Rata-Rata Bruto) dan Pertumbuhan Penduduk. Dengan variabel tersebut di atas, maka dapat dihitung volume lalu lintas rencana tahun ke - $\mathrm{n}$ dengan rumus sebagai berikut :

$$
\mathbf{Q n}=\mathbf{Q}_{\mathbf{0}}(\mathbf{1}+\mathbf{i})^{\mathbf{n}}
$$

Dimana: persamaan

$$
\text { Qn }=\text { Arus Lalu Lintas }
$$

tahun ke-n

$$
\begin{aligned}
& \mathrm{n}=\text { Umur rencana } \\
& \mathrm{i}=\text { Pertumbuhan Lalu }
\end{aligned}
$$

Lintas

$$
\mathrm{Q}_{0} \quad=\text { Arus Lalu Lintas }
$$
tahun awal / saat ini.

\section{Pengolahan dan Analisa Data}

Pada primer/ skunder yang telah ada digunakan untuk menghitung kapasitas jalan saat ini setelah dilakukan pelebaran. Kapasitas jalan kota di Indonesia dapat dihitung menggunakan persamaan :

$$
\mathbf{C}=\mathbf{C}_{\mathrm{o}} \times \mathbf{F C}_{\mathrm{w}} \times \mathrm{FC}_{\mathrm{SF}} \times \mathrm{FC}_{\mathrm{CS}} \ldots(\text { (5) }
$$

\section{Dengan :}

$\mathrm{C}=$ Kapasitas

Co = Kapasitas dasar

$\mathrm{FC}_{\mathrm{W}} \quad=$ Faktor koreksi lebar masuk

$\mathrm{FC}_{\mathrm{SP}}=$ Faktor penyesuaian

kapasitas untuk pemisah arah

$\mathrm{FC}_{\mathrm{SF}}=$ Faktor penyesuaian kapasitas untuk hambatan samping dan bahu jalan / kereb
$\mathrm{FC}_{\mathrm{CS}}=$ Faktor penyesuaian kapasitas untuk ukuran kota (jumlah penduduk).

\section{Kapasitas dan Derajat Kejenuhan Jalan}

Untuk jalan dua-lajur dua-arah, kapasitas ditentukan untuk arus dua arah ( kkombinasi dua arah ), tetapi untuk jalan dengan banyak lajur, arus dipisahkan per arah dan kapasitas ditentukan per lajur.

$$
\begin{aligned}
& \text { DS = Qsmp / C } \\
& \text { Dengan : } \\
& \text { C : Kapasitas } \\
& \text { DS : Derajat Kejenuhan } \\
& \text { Qsmp : Volume Kendaraan }
\end{aligned}
$$

\section{METODOLOGI PENELITIAN}

Dalam penyelesaian penelitian ini diperlukan langkah-langkah untuk memudahkan analisa/perhitungan.. Pada studi analisa (evalusasi) perkerasan jalan raya Glenmore Kabupaten Banyuwangi tepatnya pada KM.250-KM.252 meliputi survey pendahuluan/awal, pengumpulan data-data baik didapat dari sekunder maupun primer.

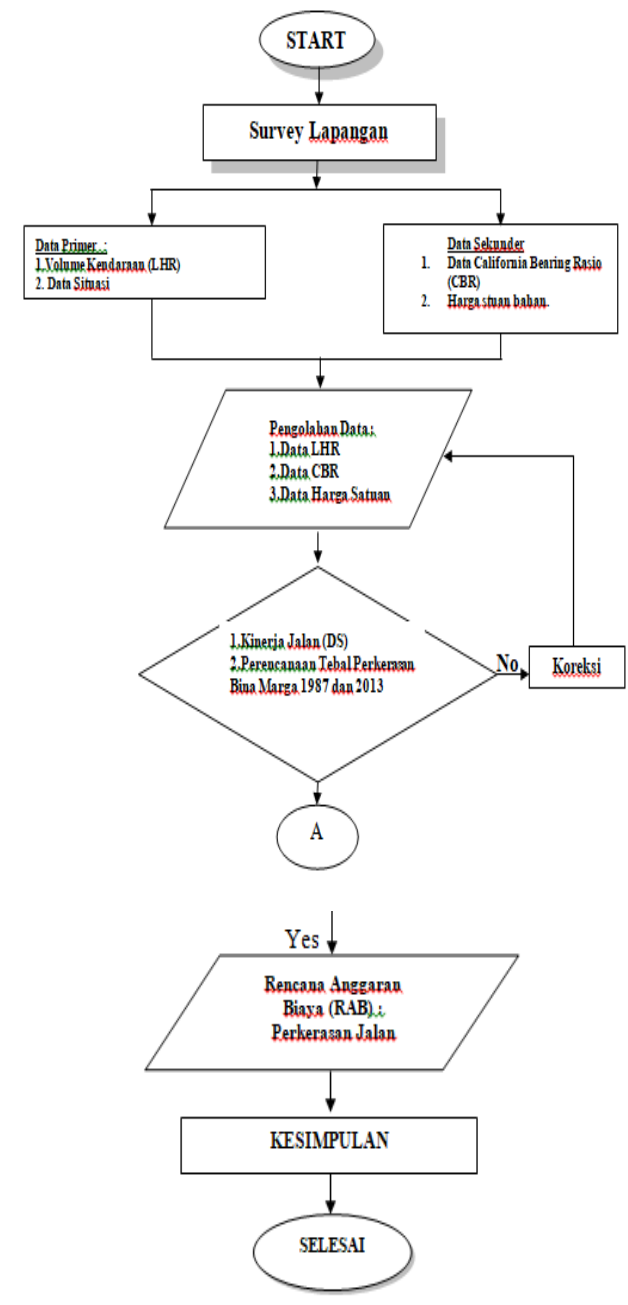

Gambar 2. Diagram Alir Penelitian 


\section{Tahapan Penelitian}

\section{Hipotesis}

Jalan raya Glenmore Kabupaten Banyuwangi pada KM.250-252 diduga belum adanya analisa (evaluasi) tebal perkerasan, mengingat lapisan perkerasan jalannya sering terjadi kerusakan jalan.

\section{Permasalahan - Permasalahan}

Dari hasil survey pendahuluan pada lokasi penelitian ini untuk mengetahui kinerja dan merencanakan tebal perkerasan serta merencanakan anggaran biaya (RAB) pada jalan raya Glenmore Kabupaten Banyuwangi pada KM.250-252.

\section{Data-data Di Jalan Raya Pengamatan LHR dan CBR}

Pada penelitian tugas akhir ini diperlukan data volume/jumlah kendaraan harian (LHR). Dari data volume kendaraan ini, nantinya akan menghitung kinerja jalan (DS). Pengamatan volume/jumlah kendaraan dilakukan secara langsung dilapangan selama 24 jam. Pengamatan ini dilakukan dengan 2 (dua) jalur atau arah kendaraan. Disamping itu diperlukan data California Bearing Rasio (CBR) yang nantinya akan digunakan untuk menghitung tebal perkerasan lentur.

\section{Perhitungan Anggaran Biaya}

Dari hasil perhitungan tebal perkerasan dari metode Bina Marga 1987 dan 2013, akan dihitung anggaran biaya (RAB) dengan harga satuan bahan yang telah ditetapkan pemerintah.

\section{Data Situasi Lokasi Penelitian}

Pendataan situasi/kondisi dilapangan dengan mengukur langsung berupa lebar badan jalan, bahu jalan, selokan-selokan/saluran, jenis bangunan (rumah/toko/tempat pendidikan/kantor, dll), sawah atau ladang disekitar lokasi penelitian secara cross section (melintang) pada lokasi penelitian.

\section{Pembahasan/Analisa Data}

Pada bagian ini, dari data lapangan yang akurasi akan dihitung tebal perkerasan dengan metode Bina Marga 1987 dan 2013. Disamping itu, dalam penelitian ini juga melakukan perbandingan anggaran biaya (RAB) pada kedua metode Bina Marga tersebut.

\section{Hasil Akhir}

Hasil pembahasan/analisa data pada jalan raya Glenmore Kabupaten Banyuwangi pada KM.250-252 yang nantinya akan didapat kesimpulan dan beberapa saran jika diperlukan sebagai pertimbangan pihak PU Bina Marga dan SDA untuk pekerjaan dilapangan (jalan).

\section{HASIL DAN PEMBAHASAN \\ Lokasi Penelitian Tugas Akhir}

Pada lokasi Penelitian Tugas akhir ini dilakukan di jalan raya Glenmore Kabupaten Banyuwangi tepatnya pada KM.250 - KM.252 atau sepanjang 2000 meter. Jalan raya Glenmore kabupaten Banyuwangi merupakan jalan arteri (kelas I) dengan lebar badan jalan $=7.00$ meter. Adapun lebar bahu jalan $1.50-$ 3.00 meter. Pada jalan raya ini terdapat kepadatan volume kendaraan bermotor. Disini pembebanan kendaraan yang besar dapat menimbulkan kerusakan pada badan jalan. Untuk mengetahui dimensi jalan, diperlukan pengukuran langsung dengan menggunakan roll meter. Gambar 3 merupakan contoh pengukuran dimensi jalan.

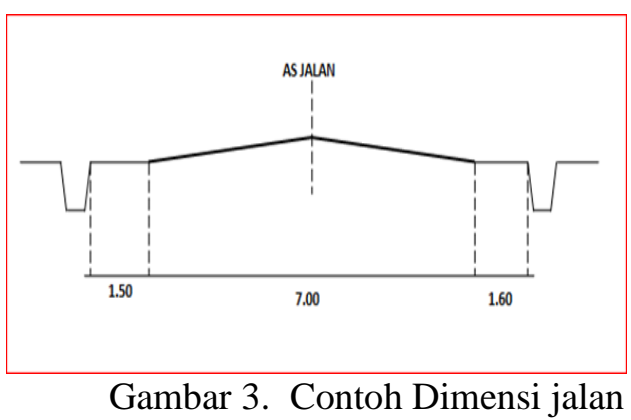

Jalan raya ini merupakan jalan penghubung Kabupaten Banyuwangi dan Jember, bahkan Jawa - Bali. Disamping itu, dengan banyaknya kendaraan berat yang melintasi akan memberi beban kendaraan pada permukaan jalan atau badan jalan-nya. Seperti diketahui kendaraan berat seperti truk, truk gandengan, trailer/semi trailer dan bus setiap hari melintasi jalan tersebut. Dengan kondisi ini, pembebanan dari kendaraan berat akan mengakibatkan kerusakan jalan. Evaluasi perhitungan tebal perkerasan lentur metode Bina Marga tahun 1987 dengan 2013 akan memberi perbandingan tebal perkerasan untuk usia rencana 20 tahun kedepan. Perhitungan Rencana Anggaran Biaya (RAB), dimaksudkan untuk memberi perbandingan anggaran dari hasil perhitungan tebal perkerasan pada kedua metode tersebut 


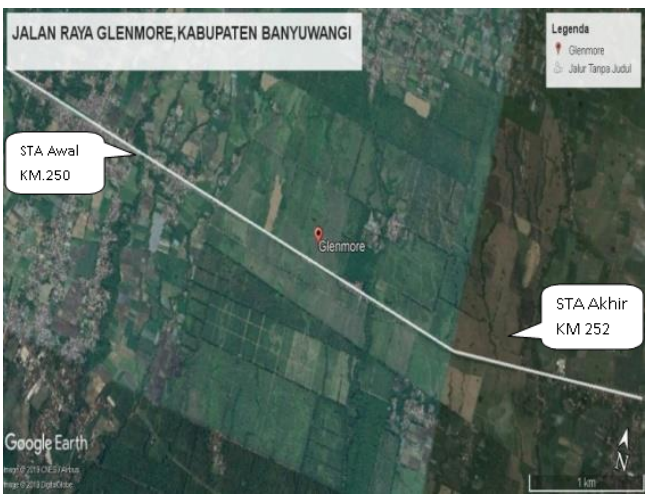

Gambar 4. Lokasi Penelitian

\section{Volume Kendaraan Jalan}

Pada data volume kendaraan ini menggunakan data-data (primer) yang berdasarkan hasil survey perhitungan atau pengamatan langsung dilapangan

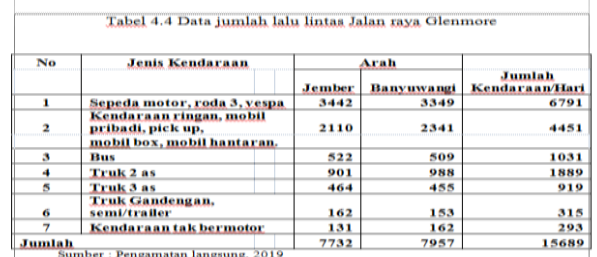

Perhitungan Perkembangan Lalu Lintas (i)

Pada penelitian ini dilaksanakan di jalan raya Glenmore Kabupaten Banyuwangi. Pada perhitungan menggunakan 2 (dua) metode yaitu Bina Marga Tahun 1987 dan 2013. Pada Bab.II Metode Bina marga 2013 terdapat nilai Usia Rencana (UR) $=20$ tahun (Tabel 2.16) dan perkembangan lalu lintas $=5 \%$ (Tabel 2.18). Hal ini untuk menyamakan \UR dan (i), maka untuk perhitungan pada kedua metode tersebut . Untuk koreksi i sebagai berikut :

$$
\begin{aligned}
& \mathrm{i}=(\mathrm{Pn} / \mathrm{Po})^{1 / \mathrm{n}}-1 \ldots \ldots .(7) \\
& \mathrm{i}=(7957 / 7732)^{1 / 20}-1 \\
& \mathrm{i}=1.4722-1=0.04911
\end{aligned}
$$

$\mathrm{i}=0.05=5 \%$. (sesuai dengan Tabel Bina Marga 2013)

\section{Analisa Kapasitas dan Derajat Kejenuhan} (DS)

Untuk mengetahui tingkat pelayanan diperlukan data LHR, Kapsitas dasar (Co) dan geometric jalan (lebar badan dan bahu jalan). Pada perhitungan Derajat Kejenuhan (DS), diperlukan nilai Kapasitas ( C) dan data LHR 2019 serta nilai Ekivalen Mobil penumpang (MKJI 1997).

\section{Perhitungan Kapasitas Jalan Tahun 2019}

Untuk nilai :
C $=$ Co $\times$ FCw $x$ FCsp $\times$ FCsf

$\mathrm{C}=3100 \times 1.00 \times 1 \times 1=3100$

Maka :

DS $_{2019}=$ Qsmp / C

$=596,5 / 3100$

$=0.192(\mathrm{~A})$

Perhitungan Kapasitas Jalan Tahun 2039

Perhitungan DS :

$\mathbf{C}=\operatorname{Co} \times \mathbf{F C w} \times \mathbf{F C s p} \times \mathbf{F C s f} \ldots \ldots(9)$

$\mathrm{C}=3100 \times 1.00 \times 1.00 \times 1.00=3100$

Maka :

DS $_{2039}=$ Qsmp $/ \mathbf{C}$

$$
\begin{aligned}
& =704,041 / 3100 \\
& =\mathbf{0 . 2 2 7 1 1}(\mathbf{B})
\end{aligned}
$$

\begin{tabular}{|c|c|c|c|c|c|}
\hline \multirow[t]{2}{*}{$\mathrm{N}_{0}$} & \multirow[t]{2}{*}{ Jenis Kendaraan } & \multirow{2}{*}{\begin{tabular}{|c|} 
Jumlah kend /hari \\
2019 \\
\end{tabular}} & \multirow[t]{2}{*}{ NilaiC } & \multirow[t]{2}{*}{ Nilie } & \multirow{2}{*}{$\begin{array}{l}\text { LEP } \\
2019\end{array}$} \\
\hline & & & & & \\
\hline 1 & $\begin{array}{l}\text { Kendaraan rigugan, mobil pribadi, pick up, } \\
\text { mobil bos, mobil hantaran. }\end{array}$ & 4451 & 0.5 & 0.0004 & 0.89 \\
\hline 2 & Bus & 1031 & 0.5 & 0.1876 & $96.70^{\circ}$ \\
\hline 3 & Truk 2as & 1889 & 0.5 & 1.3084 & 1235.78. \\
\hline 4 & Truk3 as & 919 & 0.5 & 1.229 & 564.72 \\
\hline 5 & Iruk $G$ andengan, semittrailer & 315 & 0.5 & 13.859 & 2182.79 \\
\hline Jumlal & & & & & 4080.89: \\
\hline
\end{tabular}

Perhitungan Lintas Ekivalen Permulaan (LEP), Tahun 2019

Perhitungan Lintas Ekivalen Akhir (LEA), tahun 2039

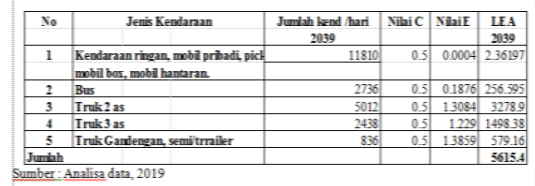

Perhitungan Lintas Ekivalen Tengah (LET)

Pada perhitungan LET

LET20 $=1 / 2($ LEP+LEA)

\begin{tabular}{|c|c|}
\hline $20=$ & LETx UR/10 \\
\hline LER20 = & $4848,1(20 / 10)$ \\
\hline LER20 & 9696.2 \\
\hline
\end{tabular}

LET20 $=1 / 2(4080,8+5615,4)$

LET $20=\mathbf{4 8 4 8 , 1}$

Perhitungan Lintas Ekivalen Rata-rata (LER)

Penentuan Indek Tebal Perkerasan (ITP)

$\begin{aligned} \text { ITP } & =a 1 D 1+a 2 D 2+a 3 D 3 \\ 6,7 & =(0.40 \times \mathrm{D} 1)+(0.13 \times 20)+(0.10 \times 20) \\ 6,7 & =(0,40 \times \mathrm{D} 1)+2,6+2 \\ & =(6,7-4,6) / 0.40 \\ \text { D1 } & =2.1 / 0.40 \\ \text { D1 } & =5,25 \mathrm{Cm}\end{aligned}$




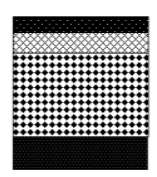

D1 $=5.25 \mathrm{~cm}$ (Laston MSS. 744 )

D2 $=20 \mathrm{~cm}$ (Batu pecah Kelas A)

$\mathrm{D} 3=20 \mathrm{~cm}$ (Batu pecah Kelas $\mathrm{B})$

CBR Tanah dasar $=17 \%$

Gambar 5. Lapisan Perkerasan,45,25 cm.

Pada tebal perkerasan kondisi dilapangan (eksisting) $=39-40 \mathrm{~cm}$, maka selisih tebal dengan perhitungan $($ analisa) $=5.25-6.25$ $\mathrm{cm}$.

Tabel 1. Perhitungan ESA4, CESA4 dan ESA5 20 Tahun

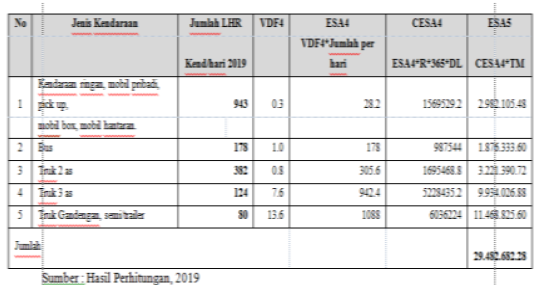

Pemilihan jenis perkerasan Pada ESA 20 tahun $=29.482 .682 .28$

Tebal lapisan perkerasan $\mathrm{AC}$ WC, AC BC, CTB, LPA Kelas A (struktur perkerasan).

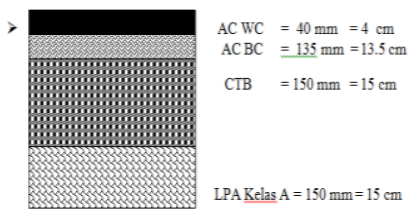

Gambar 6. Struktur Perkerasan Tebal $47.5 \mathrm{~cm}$. Pada tebal perkerasan kondisi dilapangan (eksisting) $=39-40 \mathrm{~cm}$, maka selisih tebal dengan perhitungan $($ analisa $)=7.5-8.5 \mathrm{~cm}$.

\section{Perencanaan Anggaran Biaya}

Dalam perencanaan anggaran biaya diperlukan data volume $\left(\mathrm{M}^{3}\right)$ pekerjaan. Dari hasil hitungan tebal perkerasan pada kedua metode tersebut berbeda volume $\left(\mathrm{M}^{3}\right)$ Adapun Rencana Anggaran Biaya (RAB), sebagai

berikut :

\begin{tabular}{|c|r|r|c|c|}
\hline $\mathbf{P}(\mathbf{m})$ & $\mathbf{L}(\mathbf{m})$ & $\mathbf{T}(\mathbf{m})$ & $\begin{array}{c}\text { Volume } \\
(\mathbf{m} 3)\end{array}$ & Jenis Material \\
\hline 2000 & 700 & 0.0525 & 73.500 & Laston MSS 744 \\
\hline 2000 & 700 & 0.2 & 280.000 & $\begin{array}{c}\text { Batu Pecah } \\
\text { Kelas A }\end{array}$ \\
\hline 2000 & 700 & 0.2 & 280.000 & $\begin{array}{c}\text { Batu Pecah } \\
\text { Kelas B }\end{array}$ \\
\hline Jumlah & & 633.500 & \\
Sumber: Analisa data, 2019
\end{tabular}

Tabel 1. Perhitungan Volume Pekerjaan $\left(\mathrm{M}^{3}\right)$ Metode Bina Marga 2013

\begin{tabular}{|r|r|r|r|c|}
\hline $\mathbf{P}(\mathbf{m})$ & $\mathbf{L}(\mathbf{m})$ & $\mathbf{T}(\mathbf{m})$ & $\begin{array}{c}\text { Volume } \\
(\mathbf{m} 3)\end{array}$ & Jenis Material \\
\hline 2000 & 700 & 0.04 & 56.000 & AC WC \\
\hline 2000 & 700 & 0.135 & 189.000 & AC BC \\
\hline 2000 & 700 & 0.15 & 210.000 & CTB \\
\hline 2000 & 700 & 0.15 & 210.000 & LPA Kelas A \\
\hline Jumlah & & 665.000 & \\
Sumber Analisa data, 2019 & \multicolumn{4}{l}{} \\
Sumb An
\end{tabular}

Tabel 2. Rencana Anggaran Biaya (RAB)

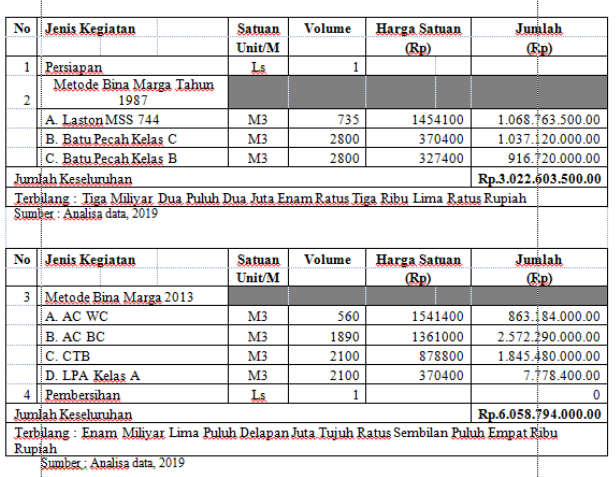

Rencana anggaran biaya dengan panjang Jalan 2000 meter dan lebar tujuh meter di jalan raya Glenmore Kabupaten Banyuwangi terdapat selisih anggran biaya pada metode Bina Marga tahun 2013 yaitu Selisih Biaya Rp.3.036.190.500.00 lebih banyak anggaran pada Metode Bina Marga 2013.

\section{KESIMPULAN DAN SARAN \\ Kesimpulan}

Dari hasil penelitian yang dilaksanakan pada jalan raya Glenmore Kabupaten Banyuwangi tepatnya di KM.250 KM.252. Pengamatan dan perhitungan terhadap data - data yang ada didapat beberapa kesimpulan sebagai berikut :

1. Dimana hasil DS $2019=0,192$ (A) Adalah kondisi arus dengan kecepatan tinggi dan volume lalulintas rendah. Pengemudi dapat memilih kecepatan yang di inginkan. Dan untuk DS $2039=$ 0.2271 (B) Adalah dalam zone harus stabil pengemudi memiliki kebebasan yang cukup untuk memilih kecepatan.

2.Dalam perencanaan tebal perkerasan lentur menggunakan metode Bina Marga, didapat hasil sebagai berikut :

Metode Bina Marga 1987 :

- Lapis Permukaan (LASTON MS 744) $=5,25 \mathrm{~cm}$

- Lapis Pondasi Atas (Batu Pecah Kelas C) $=20 \mathrm{~cm}$

- Lapis Pondasi Bawah ( Batu Pecah kelas B) $=20 \mathrm{~cm}$

Metode Bina Marga 2013 :

- $\mathrm{AC} \mathrm{WC}=4 \mathrm{~cm}$ 
- $\mathrm{AC} \mathrm{BC}=13.5 \mathrm{~cm}$

- $\mathrm{CTB}=15 \mathrm{~cm}$

- $\quad$ LPA Kelas A $=15 \mathrm{~cm}$

3.Dalam rencana anggaran biaya dengan Panjang Jalan 2000 meter dan lebar 7 meter, didapat :

- Metode Bina Marga 1987 Rp.3.022.603.500.00

- Metode Bina Marga 2013 Rp.6.058.794.000.00

Selisih Biaya Rp. Rp.3.036.190.500.00 lebih banyak anggaran pada Metode Bina Marga 2013.

\section{SARAN}

Saran dalam penelitian ini adalah sebagai berikut :

1. Perlunya pemeliharaan dan pengawasan jalan Glenmore Kabupaten Banyuwangi KM.250 - KM.252, terutama kendaraan yang melintas (beban) angkutan.

2. Untuk pembangunan atau peningkatan jalan, diperlukan evaluasi ulang untuk tebal perkerasannya, mengingat jalan tersebut merupakan jalan penghubung antar kabupaten dan provinsi (Jawa-Bali)

\section{REFRENSI}

Alamsyah, Alik Ansyori, Ir,MT., Rekayasa Jalan Raya , Universitas Malang, 2001 Muhammadiyah Malang Press,

Direktorat Jenderal Bina Marga. 1997. Dep. PU dan TL., Tata Cara Perencanaan Geometrik Jalan Antar Kota, Jalan No. 038/TBM/1997, Jakarta.

Ilmu Ukur Tanah, Unmuh Jember, 2005.

Manual Kapasitas Jalan Indonesia (MKJI). 1997. Direktorat Jenderal Bina Marga.

Petunjuk Pelaksanaan Laston Untuk Jalan Raya SKBI - 2.4.26.1987.

Saodang Hamirhan, 2005 "konstruksi jalan raya",Penerbit : Nova Bandung.

Silvia Sukirman, 2010 Perencanaan Tebal Perkerasan Lentur, Penerbit : Nova Bandung.

Teknik, Bina Marga 1987. Analisa Pekerjaan Jalan dan Jembetan. Direktur Bintek.

Jakarta.

Teknik. Bina Marga 2013. Analisa Pekerjaan Jalan dan Jembetan. Direktur Bintek. Jakarta. 